\title{
Plasmodium knowlesi and Wuchereria bancrofti: their vectors and challenges for the future
}

\author{
Indra Vythilingam* \\ Parasitology Department, Faculty of Medicine, University of Malaya, Kuala Lumpur, Malaysia
}

Edited by:

Rubén Bueno-Marí, University of

Valencia, Spain

Reviewed by:

Sylvie Manguin, Institute of Research for Development, France

Balbir Singh, Universiti Malaysia

Sarawak, Malaysia

*Correspondence:

Indra Vythilingam, Parasitology Department, Faculty of Medicine,

University of Malaya, 50603 Kuala Lumpur, Malaysia.

e-mail: indrav@um.edu.my
Malaria and filariasis still continue to pose public health problems in developing countries of the tropics. Although plans are in progress for the elimination of both these parasitic vector borne diseases, we are now faced with a daunting challenge as we have a fifth species, Plasmodium knowlesi a simian malaria parasite affecting humans. Similarly in peninsular Malaysia, filariasis was mainly due to Brugia malayi. However, we now see cases of Wuchereria bancrofti in immigrant workers coming into the country. In order to successfully eliminate both these diseases we need to know the vectors involved and introduce appropriate control measures to prevent the diseases occurring in the future. As for knowlesi malaria it is still uncertain if human to human transmission through mosquito bites is occurring. However, $P$. knowlesi in human is not a rare occurrence anymore and has all the characteristics of a pathogen spreading due to changes in the ecosystem, international travel, and cross border migration. This has created a more complex situation. In order to overcome these challenges we need to revamp our control measures. This paper reviews the vectors of malaria and filariasis in Southeast Asia with special emphasis on $P$. knowlesi and $W$. bancrofti in Malaysia and their control strategies.

Keywords: Plasmodium knowlesi, Wuchereria bancrofti, Southeast Asia, vectors, control

\section{INTRODUCTION}

Malaria and filariasis are the two most important mosquito borne parasitic diseases on a global scale. Currently about $40 \%$ of the global population remains at risk of contracting malaria (Hay and Snow, 2006) and 1000 million people in 80 countries are at risk of contracting filariasis (Zagaria and Savioli, 2002). Besides Africa, Asia contributes to a large number of cases (Bockarie et al., 2009). In 1998 World Health Organization (WHO) embarked on a program for global elimination of lymphatic filariasis and this was followed by elimination of malaria program in 2006. This review will be confined mainly to Southeast Asia and with special reference to Plasmodium knowlesi and Wuchereria bancrofti.

Human malaria has been known to be caused by four Plasmodium species namely $P$. falciparum, $P$. vivax, $P$. malariae, and $P$. ovale. However, of late $P$. knowlesi, a simian malaria parasite is also affecting humans mainly in Southeast Asia region (Singh et al., 2004; Cox-Singh et al., 2008; White, 2008; Galinski and Barnwell, 2009). The first case of $P$. knowlesi in human was reported in an American surveyor who contracted the disease in the jungles of Pahang in peninsular Malaysia in 1965 (Chin et al., 1965) and subsequently the second suspected case of $P$. knowlesi was reported from Johore (Fong et al., 1971). Extensive studies carried out during the 1960s did not reveal further cases (Warren et al., 1970) and thus the conclusion drawn at that time was that $P$. knowlesi will not affect humans and the first case was just a rare incident. However, laboratory studies carried out then also revealed that monkey to human transmission through mosquito bites can take place (Chin et al., 1968; Contacos, 1970).

About four decades later, Singh et al. (2004) reported 106 cases of $P$. knowlesi that were misdiagnosed as $P$. malariae and in addition there were mixed infection of $P$. knowlesi and $P$. falciparum and P. vivax in Sarawak, Malaysian Borneo. Currently knowlesi malaria has been reported from all countries in Southeast Asia with the exception of LAO PDR. (Jongwutiwes et al., 2004; Zhu et al., 2006; Cox-Singh et al., 2008; Luchavez et al., 2008; Vythilingam et al., 2008; Van den Eede et al., 2009; Sulistyaningsih et al., 2010; Khim et al., 2011). Morphologically it is difficult to distinguish between the band stage of $P$. malariae with $P$. knowles $i$ and the ring stage of $P$. falciparum with $P$. knowlesi (Lee et al., 2009b). Using molecular tools to study the archival blood samples from patients in Sarawak obtained more than a decade ago (in 1996) demonstrated that $P$. knowlesi was occurring there for a long time and was not detected (Lee et al., 2009a). Further studies on blood samples from macaques and the analysis of the mitochondrial DNA showed that $P$. knowlesi underwent a period of population expansion estimated to about 30,000-40,000 years ago (Lee et al., 2011). Studies in Thailand have shown that $P$. knowlesi occurred in humans more than a decade ago (Jongwutiwes et al., 2011).

When the human case was detected in 1965 in peninsular Malaysia, studies were also conducted to elucidate the host and the vectors. This led to many new simian malaria parasites being described (Eyles et al., 1962a,b). P. knowlesi was found in Macaca fascicularis, M. nemestrina, and Presbytis melalophos.

Detailed studies on vectors of simian malaria were also conducted in peninsular Malaysia in the 1960s. In the coastal mangrove swamp areas of Selangor, Anopheles hackeri was incriminated as the vector of $P$. knowlesi (Wharton and Eyles, 1961). However, this species of mosquito was found biting only monkeys. None came to bite humans. In laboratory studies $A$. hackeri was able 
to transmit five species of simian malaria namely $P$. cynomolgi, $P$. inui, P. coatneyi, P. fieldi, and P. knowlesi (Warren and Wharton, 1963). Extensive studies were carried out using monkey baited traps on platforms among foliage of trees at different heights. Detailed records of the vector distribution and studies has been published (Vythilingam, 2010). In the area where the first case was found in Bukit Kertau Pahang, peninsular Malaysia, A. introlatus and $A$. latens were obtained from the forest but not in the village (Warren et al., 1970). In the sixties since molecular techniques were not available, in order to confirm species of sporozoites they were inoculated into rhesus monkeys. A. balabacensis (=A. cracens; Sallum et al., 2005a) a vector of human malaria was incriminated as vector of $P$. inui (Cheong et al., 1965).

Lymphatic filariasis is caused by three species of parasites namely Brugia malayi, W. bancrofti, and to a lesser extent B. timori. Although Asia has an estimated total at-risk population of $68 \%$ for LF, it is by far the most important region globally in terms of number of active filarial infections, contributing approximately $59 \%$ of the world's burden distributed over 15 countries (Manguin et al., 2010). More than $70 \%$ of the LF cases occur on the Indian subcontinent, particularly India, Bangladesh, Maldives, Nepal, and Sri Lanka (Manguin et al., 2010). Migrant workers from these countries go to work in neighboring countries and there is every possibility that microfilariae will be brought along with them.

Rural strain (present only in very remote rural areas of peninsular Malaysia in rural villages of Sabah and Sarawak) of W. bancrofti is present in Malaysia but the urban strain is not common (Mak, 1981). Attempts by workers to establish patent infection of $W$. bancroft $i$ in animals have so far been unsuccessful. However, Cross et al. (1974) and Dissanaike and Mak (1980) were able to recover adult worms from experimental infections in Taiwan Monkeys (M. cyclopis) and M. fascicularis respectively. They found gravid females with active microfilariae in the uterus but none were found in the blood.

Unlike malaria where only few species of the Anopheles genus are vectors, vectors of filariasis belong to species of six mosquito genera, such as Aedes, Anopheles, Culex, Downsiomyia, Mansonia, and Ochlerotatus, in the Southeast Asia region (Mak, 1987).

\section{VECTORS OF SIMIAN MALARIA}

Although simian malaria was known to occur in the forest of Southeast Asia way back in the 1960s not much is known about the vectors except in Malaysia. The mosquitoes incriminated as vectors belong to the Leucosphyrus group (Wharton et al., 1964) and it was noted that simian malaria parasites developed poorly in the subgenus Anopheles. In India, A. elegans now known as $A$. mirans (Sallum et al., 2005b; also a member of leucosphyrus gr) was incriminated as vector for simian malaria $P$. cynomolgi and $P$. inui (Choudhury et al., 1963).

The first simian malaria vector to be incriminated was $A$. hackeri and five species of plasmodia were isolated namely $P$. knowlesi, $P$. coatneyi, P. cynomolgi, P. fieldi, and P. inui (Wharton et al., 1964). A. hacker $i$ was found mainly in the coastal area and was not attracted to humans. It was also found in Southern Thailand and in the Philippine islands of Balabac and Palawan (Sallum et al., 2005a) but its role as vector of simian malaria in those areas have not been investigated.
Within the Leucosphyrus complex, A. latens was incriminated as vector of $P$. inui in the hill-forest feeding mostly at the canopy level (Wharton et al., 1964). A. introlatus was incriminated as vector for $P$. cynomolgi and $P$. fieldi and it rarely feeds on man (Wharton et al., 1964). While in the northern part of peninsular Malaysia $A$. cracens $(=A$. balabacensis $=$ A.dirus B) was found infected with $P$. cynomolgi and P. inui (Cheong et al., 1965). Laboratory studies also showed that $A$. cracens was a much better vector of malaria parasites compared to other species since $77 \%$ of them were infected (Scanlon, 1968).

Recent studies carried out in Pahang incriminated $A$. cracens to be a vector of $P$. knowlesi (Vythilingam et al., 2008). Early studies showed A. cracens to be strongly exophilic and exophagic, they avoid contact with sprayed surfaces and contact with humans take place away from the dwellings. The peak feeding was not long after dusk (Scanlon, 1968). After many decades it shows that A. cracens has not changed its behavior and in our study we found that it does not enter houses and starts biting humans around 19:00-20:00 h. It also shows preference to bite humans compared to macaques, ratio being 2:1 (Vythilingam et al., 2008).

Besides Malaysia, A. cracens occurs in Indonesia (Sumatra) and Thailand (Sallum et al., 2005a). However, their vectorial status in these two countries remains unknown. Currently only the $A$. leucosphyrus group has been incriminated as vectors of simian malaria. In Kapit, Malaysian Borneo, A. latens has been incriminated as vector of $P$. knowlesi (Vythilingam et al., 2006; Tan et al., 2008) and four simian malaria parasites namely P. inui, P.coatneyi, P. fieldi, and P. cynomolgi (Tan, 2008). A. latens has shown different biting times in the forest and farm. In the forest, they are early biters, peak being between 19:00 and 20:00 while in the farm the peak is 01:00-02:00 h (Tan et al., 2008). A. latens was the predominant species coming to bite both humans and macaques in the forest.

In other parts of Southeast Asia, besides Malaysia, vectors have been elucidated in Vietnam. Studies have shown A. dirus to be the main vector of P. knowlesi (Nakazawa et al., 2009; Marchand et al., 2011). The most interesting part of their study was that mixed infection with human malaria and $P$. knowlesi parasites were found in $A$. dirus. This could be due to the fact that malaria parasites are still circulating in the human population living in the forested areas. In Malaysia although mixed infection of knowlesi malaria and other human malaria were found in patients, we never obtained such mixed infection in mosquitoes. This could be due to the fact that our study was confined to two areas in Pahang where human malaria has been eliminated and thus mixed infection could not be detected. Perhaps more extensive surveys need to be carried out in areas where mixed infections of human and simian malaria parasites are being found.

Anopheles dirus is the vector of human malaria in Thailand, Cambodia, Laos, and Vietnam (Chareonviriyaphap et al., 2000; Vythilingam et al., 2003; Trung et al., 2004; Manguin et al., 2008) and it belongs to the Leucosphyrus group which has its main distribution in the Oriental region (Harbach, 2004; Subbarao, 2007; Figure 1). In Thailand cases of knowlesi malaria have been reported but the vector has not been incriminated (Seethamchai et al., 2008). The main vectors of human malaria in Thailand are A. minimus, A. maculatus, and A. dirus 

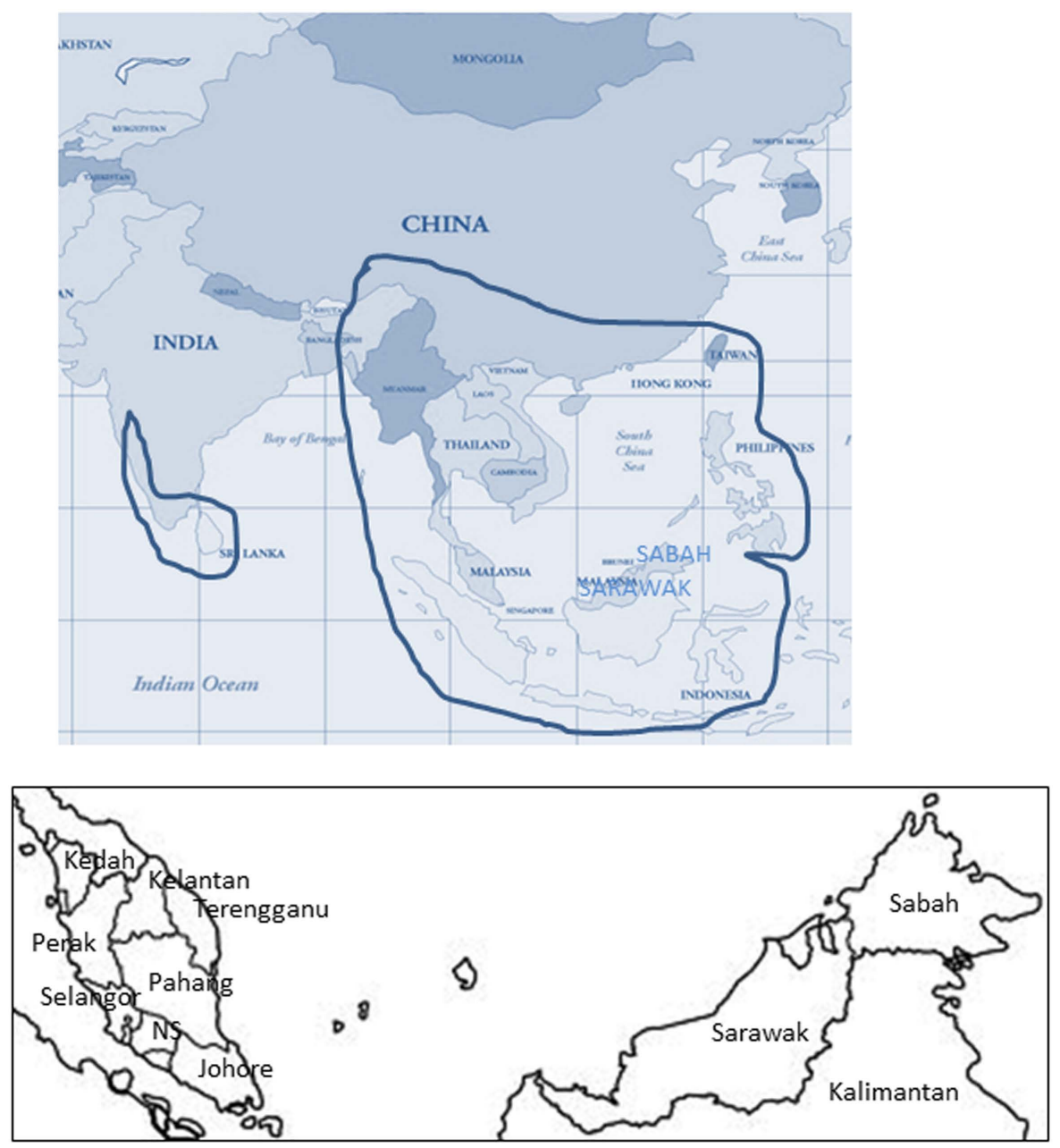

FIGURE 1 | Map of South and Southeast Asia showing distribution of an leucosphyrus group of mosquitoes. Insert showing the map of Malaysia. Adapted from Sallum et al. (2005a).

(Chareonviriyaphap et al., 2000). However, recently A. dirus has drastically decreased in abundance in major malaria endemic areas of Thailand (Jongwutiwes et al., 2011).

\section{VECTORS OF BANCROFTIAN FILARIASIS}

The three variants of $W$. bancrofti found in human are recognized by the periodicity of the microfilaria in the blood. It can be nocturnally periodic, nocturnally subperiodic, and diurnal subperiodic (Mak, 1987). Species of mosquitoes belonging to the six genera of mosquitoes listed above are vectors (Zagaria and Savioli, 2002). It has also been suggested that Southeast Asia may have been the home of this parasite and may have been disseminated to the other continents from here (Hawking, 1976). Thus, Malaysia is vulnerable to the establishment of $W$. bancrofti in both urban and rural areas because the migrant populations coming from filariasis endemic countries work in both urban and rural areas such as plantations. The vectors associated with these parasites are mainly Anopheles mosquitoes in the rural areas and C. quinquefasciatus in the urban areas. In Banggi Island (north-eastern Sabah, Malaysia),
A. balabacensis and A. flavirostris have been reported as vectors of malaria and Bancroftian filariasis and responsible for maintaining holo- to hyper-endemic levels of both diseases (Hii et al., 1985). In Sarawak (Malaysian Borneo), A. barbirostris, A. donaldi, A. letifer, and A. latens (formerly A. leucosphyrus A; Sallum et al., 2005a), are considered vectors for malaria and Bancroftian filariasis (Chang et al., 1995; Rahman et al., 1997). In Palau Aur (off the Southern State of Johore in peninsular Malaysia $2^{\circ} 26^{\prime} 57^{\circ} \mathrm{N} 104^{\circ} 31^{\prime}$ $\left.30^{\circ} \mathrm{E}\right)$ A. maculatus has been incriminated as the vector of $W$. bancrofti (Cheong and Omar, 1965). A. maculatus is also the vector of human malaria in peninsular Malaysia. With the decrease in human malaria cases, and with an influx of migrant workers, it is probable that $A$. maculatus may develop into an efficient vector for bancroftian filariasis. This is based on evidence that majority of mosquitoes that pick up mixed malarial and filarial pathogens do not live long enough for the two parasites to reach the infective stage (Muturi et al., 2006). Culex quinquefasciatus is the main vector of urban bancroftian filariasis in countries like India (Das et al., 1992), Sri Lanka (Amerasinghe and Munasingha, 1988), and 
also Thailand (Triteeraprapab et al., 2000). Recent studies have shown that the local strain (Malaysian) of C. quinquefasciatus is susceptible to the Myanmar strain of W. bancrofti (Vythilingam et al., 2005b). This species easily invades suitable habitats and once established it is difficult to control them. Due to changing ecological landscape some species may have been displaced and suitable habitats may have been created for others. Thus, more work is needed to study the species composition of the mosquitoes so that the bionomics, ecology, and epidemiological importance of these vectors will be known.

\section{CONTROL OF VECTORS OF SIMIAN MALARIA AND BANCROFTIAN FILARIASIS}

It has been accepted that insecticides treated bed nets (IBN) play an important role in the prevention of malaria. In Africa, it has been shown that with the use of treated nets for every 1000 children protected about 5.5 lives can be saved in children below 5 years (Lengeler, 2004). In Asia and Latin America, it has been shown that the clinical episodes of malaria have been reduced in areas where there is low transmission of malaria and where the entomological inoculation rate is below one. Control activities for the control of malaria vectors, be it adults or larvae were always carried out. For adults, indoor residual spraying (IRS) was conducted using DDT at $2 / \mathrm{gm}^{2}$. With the use of IRS followed by cases detection and treatment, some countries like Singapore managed to eliminate malaria and obtained malaria free status by WHO in 1983 (Goh, 1983). However, sporadic cases do occur from time to time (Ng et al., 2010).

In Malaysia, anti-larval works for malaria control was actively carried out starting during Watson's time in 1921 and continued during the 1950's. Malaya can claim the honor of being one of the earliest countries in the world to have successfully applied the knowledge of the mode of transmission of malaria to its control (Sandosham, 1984). Many environmental modification techniques were applied to larval habitats to control the breeding of the vectors. Subsoil pipes, automatic siphon, environmental modification techniques were some of the methods that were used so that Anopheles mosquitoes would not be able to breed (Singh and Tham, 1988). These were permanent measures that were used to reduce the number of breeding sites. Earth drains were also maintained and these drains were regularly sprayed with malaria GD oil and later with Abate 500E. However, in the hilly areas where A. maculatus was the main vector, it was difficult to reduce the number of breeding sites.

Currently A. latens is the vector of knowlesi malaria in Kapit, Sarawak (Vythilingam et al., 2006) and is also the vector of human malaria in Sarawak (Seng et al., 1999). Thus, existing control activities for A. latens should be able to reduce malaria cases. However, the indoor:outdoor biting activity of A. latens shows that they are more exophagic. In our study, infected mosquitoes were not obtained from the long house (where native Sarawakians live; Tan et al., 2008). Thus, perhaps people were getting infected either in the forest or in the farms where they work.

In peninsular Malaysia, $A$. cracens does not enter houses to bite (Scanlon and Sandhinand, 1965) and thus the conventional IBN or
IRS will not work. These mosquitoes are also early biters and thus people get bitten while outside their homes in the late evenings or while carrying out forest activities or camping outdoors in forested areas.

However, in Vietnam $A$. dirus has been incriminated as vector of knowlesi malaria and is also the vector of human malaria (Nakazawa et al., 2009; Marchand et al., 2011). It has been documented that the use of IBN and treated hammocks have been instrumental for the reduction of malaria cases (Thang et al., 2009). Thus, this could be one reason why there are only a few knowlesi cases in Vietnam. In Malaysia, existing control measures (IRS and IBN) will not be able to control the vectors of knowlesi malaria due to their exophagic and exophilic behavior. Also in areas where knowlesi malaria is occurring people may have lost their immunity since it is malaria free and thus easily prone to the disease. Perhaps cross-species protection from the established malaria parasites prevented the entry of $P$. knowlesi into the human population (Conway, 2007).

Although vector control measures have been instituted for malaria along with case detection and treatment, for filariasis it has been mainly treatment and Mass Drug Administration (MDA) without any special vector control measures. Control measures have not been instituted specifically for filariasis. In areas where Anopheles spp. were vectors of filariasis, it was felt that control measures instituted for malaria vectors will also control filariasis vectors. In the same way where the Aedes mosquito is responsible for dengue and filariasis, measures taken for dengue control will also benefit filariasis. In areas where Mansonia were vectors for filariasis, very little has been done but with development many of the breeding sites have been destroyed.

In Africa where A. gambiae is the vector for both diseases it has been observed that with the Diethylcarbamazine (DEC) there has been a reduction of filariasis and this led to the increase in the infection rate of malaria parasites since the longevity of the mosquito increased (Muturi et al., 2006). It has always been a challenge that MDA alone will not be able to eradicate filariasis and using vector control alone some countries, like Solomon Island, has been successful in the elimination of filariasis (Bockarie et al., 2009). In studies carried out in periodic B. malayi areas it was shown that with DEC normal treatment regimen or single dose treatment was able to reduce the prevalence of microfilariae (Hakim et al., 1995). However, the infective bites per month of the vector $A$. donaldi was higher after treatment, though not significantly different before and after treatment (Vythilingam et al., 1996). This shows that perhaps not all people received treatment due to inaccessibility of terrain. Thus, it would be ideal to include MDA and vector control where feasible in a control program.

\section{OPERATIONAL ISSUES REGARDING ELIMINATION OF MALARIA AND FILARIASIS}

World Health Organization has now embarked on a global scale to eliminate filariasis and malaria. Thus, countries are now gearing up the activities to eliminate the two diseases. In Southeast Asia, it has been shown that knowlesi malaria is zoonotic, potentially fatal, and widely distributed (Cox-Singh and Singh, 2008). Although in the 1960's it was thought that the first natural infection 
was a rare incidence, it was postulated that when human malaria cases reach a low level, the possibility of human population being infected with simian malaria parasites could be significant (Chin et al., 1968). It has also been argued that there is every possibility that other simian malaria like P. cynomolgi and $P$. inui can also be transmitted to humans (Baird, 2009). When malaria is eliminated from a place, there lurks danger for simian malaria to be transmitted to humans. This is currently occurring in parts of peninsular Malaysia (Vythilingam et al., 2008).

In most areas in peninsular Malaysia, knowlesi malaria is occurring in malaria free areas. This could be due to two reasons: people have lost their immunity and secondly it is not possible to treat the animal host and thus a pool of parasites is always available for transmission to human host as long as the suitable Anopheles vector is present.

Wuchereria bancrofti is responsible for $90 \%$ of all human lymphatic filarial infection. India alone accounts for 45.5 million cases (WHO, 2010). In Southeast Asia, Indonesia has about 28.5 million cases (Rusmartini and Yuliantina, 2008) and has both W. bancrofti and Brugian filariasis. Filariasis has always been a neglected disease of the poor population with people getting infected during childhood and showing the symptoms during later stages in life (Witt and Ottesen, 2001). Cheap international travel and cross border migration allows the parasites to be easily brought into the countries, and with suitable vectors, it is possible for transmission to take place. Studies have also shown that with MDA there was a reduction in the prevalence of filariasis. However, when MDA was stopped the cases slowly started to increase due to the few that did not undergo treatment and harbored the microfilaria. Besides, since vector control was not carried out, it led to the increase (Cartel et al., 1992; Esterre et al., 2001; Sunish et al., 2002). Thus, multiple rounds of MDA in many countries did not achieve the predicted interruption in transmission since vector control has not been implemented (Bockarie et al., 2009).

As for the vectors there was also evidence where the same mosquito was able to transmit both filariasis and malaria pathogens (Manguin et al., 2010). Studies have shown that co-infection with both parasites was possible and sporozoites were found in higher numbers in A. gambiae when third stage bancroftian larvae were present but the survival rate of the mosquitoes were lower in Kenya (Muturi et al., 2006). Other studies in Papua New Guinea have shown that less malaria parasites will develop in mosquitoes with filarial worms (Aliota et al., 2011), thus, there may be a possibility that more cases of malaria will occur once filariasis is eliminated. However, studies are needed in the Southeast Asia to confirm if the vectors will exhibit similar modes of infection as shown in Africa or Papua New Guinea.

Predicting an outbreak is always difficult. Control and surveillance is always carried out after the outbreak and when many lives are lost (Petney et al., 2009). Simian malaria in humans is life threatening and mortality has been reported (Cox-Singh et al., 2008; Barber et al., 2011). Thus, in the case of malaria at least after a few lives have been lost, public health alert will be instituted and the outbreak will be brought under control. It is very difficult to maintain surveillance system once it has been declared that the disease has been eliminated. It needs a lot of commitment from government bodies to have a proper surveillance after elimination. While in the case of filariasis, the disease does not cause mortality and thus people who get infected will only know when they have reached the incurable stage. By this time they would have passed the infection to mosquitoes and silent transmission will be on-going.

When Plasmodium parasites are host specific Anophelism without malaria is possible, but with zoonosis, a pool of parasites will always be available and the elimination of the parasite is not an easy task. With deforestation and changes in the environment it is possible for new vectors to displace the established vectors. One good example is A. maculatus which was the predominant mosquito obtained in malaria vector surveys in the past in peninsular Malaysia (Sandosham and Thomas, 1983; Chiang et al., 1991; Vythilingam et al., 1993, 1995; Rahman et al., 1997). However, a survey carried out after the occurrence of knowlesi malaria shows that $A$. cracens is the predominant mosquito and was never reported previously from Pahang (Vythilingam et al., 2008). How far A. cracens has spread within peninsular Malaysia is not known. It may be possible that $A$. cracens followed the long tailed macaques from the forest and have now colonized the villages. When these changes occur, the existing control measures may not be sufficient to reduce vector density due to exophagic and exophilic behavior of the vectors. When such changes take place, it is always important to study the mosquito fauna in that area. Changes in land use can sometimes help in the reduction of malaria. One good example is in Thailand where deforestation in the north-eastern part of the country led to a reduction of malaria as $A$. dirus population was reduced since this mosquito needs shaded environment for survival and reproduction (Petney et al., 2009).

In Sabah, Malaysian Borneo, studies carried out in the Kinabatangan area showed that $A$. balabacensis was the main vector for malaria (Hii et al., 1985). However, after two decades, studies carried out in that same area found $A$. donaldi to be the predominant mosquito and was found positive for sporozoites (Vythilingam et al., 2005a). A. donaldi is not an efficient vector like $A$. balabacensis. Currently what has been observed is that in areas where human malaria cases have been reduced, knowlesi malaria transmission is occurring in the population. In Kudat, there was a major reduction in slide positivity rate and parasite rate from 1990 to 1991 due to the establishment of primary health care volunteers (Hii et al., 1996). Kudat is a coastal rural farming area with minimal regrowth of forest and in 2009, 137 $(87 \%)$ cases of $P$. knowlesi was diagnosed in that region and 24 (14\%) occurred in children (Barber et al., 2011). Extensive studies are needed to know the vectors involved so that control measures can be instituted where possible. Here is an example of how reduction of human malaria and changes in land use has the potential to facilitate the transmission of knowlesi malaria to humans. Thus, understanding the changes is critical for a control program and also the information on vectorial capacity of the mosquitoes is important and should be included as a criteria in malaria elimination.

Vectors too can change from being primarily zoophilic to primarily anthropophilic. A good example is A. sinensis in peninsular Malaysia which was primarily zoophilic and therefore has not 
been considered a vector (Reid, 1968). Currently in Singapore $A$. sinensis has been the predominant species attracted to humans in areas where malaria cases were reported (Ng et al., 2010). Due to the changes in the behavior perhaps $A$. sinensis could be a vector for malaria. Changes in temperature also affect the lifecycle of the mosquito and the parasite. It is known that an increase in temperature shortens the lifecycle of the mosquito and also the development of the parasite within it (Gage et al., 2008). Thus, currently with an increase in temperature compared to five decades ago, perhaps a smaller number of mosquitoes may be more efficient in disseminating the parasites since time taken for the development of the infective stage is reduced.

Unlike the malaria parasite, the filarial parasite does not multiply in the body of the mosquito. It has been postulated from a study in Rangoon that a person needs to be bitten 15,500 times by infective mosquitoes before becoming positive (Hairston and De Meillon, 1968). This is for $W$. bancrofti transmitted by $C$. quinquefasciatus. However, 60 million cases are reported in Asia and Southeast Asia (WHO, 2010) and majority being W. bancrofti. Extensive vector control will help to reduce the infection rate and should be a priority in countries with large number of cases.

In the filariasis elimination program it is important that the surveys are properly carried out and that coverage of the population should be adequate. Since vector control activities have not been carried out in most countries, any person harboring the parasite or an immigrant with parasites entering the area can lead to silent transmission as infection will not be known for many years to come. The surveillance for this disease would be forgotten as it is more of psychosocial problem (Ottesen et al., 1997; Dreyer et al., 2000).

In Malaysia, currently more than $70 \%$ of the filariasis cases are imported into the country (unpublished document). C. quinquefasciatus is susceptible to the W. bancrofti (Vythilingam et al., 2005b). The migrant workers live both in the urban and rural areas such as plantations and since vectors are present, the dissemination of the parasite to the local population is possible. This is also of concern in Thailand where it has been reported that the prevalence of patent $W$. bancrofti infection in Myanmar immigrants has prompted concern in the public health community that the potential now exists for a re-emergence of Bancroftian filariasis in Thailand (Triteeraprapab et al., 2000).

\section{CHALLENGES FACING SOUTHEAST ASIA AND THE RISK OF THESE TWO DISEASES}

Naturally acquired cases of $P$. knowlesi have been reported from travelers visiting this region as shown in Table 1 . These people have brought back the parasites to Australia, New Zealand, Europe, and USA from Southeast Asia (Kantele et al., 2008; Mali et al., 2008; Bronner et al., 2009; Figtree et al., 2010; Tang et al., 2010; Berry et al., 2011; Hoosen and Shaw, 2011).

Thus, it has still not been established if human to human transmission is taking place. However, it is very clear that cases of knowlesi malaria can no longer be considered single episodic cases but represent true health care emergency (Sabbatani et al., 2011). This goes to show that travel to Southeast Asia can help to spread the parasites to other countries. For example India has

\section{Table 1 | Distribution of knowlesi malaria cases acquired from} Southeast Asia by foreign visitors

\begin{tabular}{|c|c|c|c|}
\hline No & $\begin{array}{l}\text { Country of } \\
\text { origin }\end{array}$ & $\begin{array}{l}\text { Place where contracted } \\
\text { the disease }\end{array}$ & Reference \\
\hline 1 & $\begin{array}{l}\text { New } \\
\text { Zealand }\end{array}$ & $\begin{array}{l}\text { Sabah, Sarawak (Malaysian } \\
\text { Borneo) }\end{array}$ & Hoosen and Shaw (2011) \\
\hline 2 & USA & Palawan, Philippines & Mali et al. (2008) \\
\hline 3 & Finland & $\begin{array}{l}\text { North west of peninsular } \\
\text { Malaysia }\end{array}$ & Kantele et al. (2008) \\
\hline 4 & Sweden & $\begin{array}{l}\text { Bario Highland, Sarawak, } \\
\text { Malaysia }\end{array}$ & Bronner et al. (2009) \\
\hline 5 & Spain & $\begin{array}{l}\text { Forest areas of Southeast } \\
\text { Asia }\end{array}$ & Tang et al. (2010) \\
\hline 6 & France & Thailand & Berry et al. (2011) \\
\hline 7 & Australia & $\begin{array}{l}\text { Kalimantan, Indonesian } \\
\text { Borneo }\end{array}$ & Figtree et al. (2010) \\
\hline
\end{tabular}

common border with Bangladesh, Bhutan, Myanmar, and Nepal. Of these Myanmar is endemic for knowlesi malaria (Jiang et al., 2010) and the leucosphyrus group of mosquitoes are present in India. Thus there will be ample occasions for the parasite to be brought into India (Subbarao, 2011). Many countries may still be unaware or do not have molecular tools to detect $P$. knowlesi and thus this parasite may be silently spreading to the region and beyond. It is important for visitors to know about the dangers of getting infected when they are out in the forested areas of Southeast Asia. The most recent report includes cases from the south western border of Thailand with Myanmar (Sermwittayawong et al., 2012).

As for Bancroftian filariasis, immigrant workers from endemic countries will be able to bring the disease as they are not screened at the point of entry. Perhaps now that elimination of filariasis is ongoing it would be prudent to have some surveillance mechanism in place.

\section{CONCLUSION}

Although countries in the region are gearing toward elimination of malaria and filariasis, emphasis should include a combination of tools to control the disease and the vectors. It should also be noted that the current control strategies for vectors may not be applicable or appropriate due to changes in vectors and their behavior or changes in parasites. More studies should be carried out in the region to establish if human to human transmission of knowlesi malaria is occurring. Vectors of simian malaria throughout the region should be identified so that appropriate control measures and new strategies can be instituted where possible. Migrant workers need to be screened for filariasis and it is important to establish if silent transmission is occurring in areas where these migrant population live in large numbers. Thus, vector studies should be extensive and focused so as to provide evidence based solutions to these emerging and complex vector borne diseases.

\section{ACKNOWLEDGMENTS}

The author would like to thank John Jeffery and the anonymous reviewers for their constructive comments of the manuscript. 


\section{REFERENCES}

Aliota, M. T., Chen, C. C., Dagoro, H., Fuchs, J. F., and Christensen, B. M. (2011). Filarial worms reduce Plasmodium infectivity in mosquitoes. PLoS Negl. Trop. Dis. 5, e963. doi:10.1371/journal.pntd.0000963

Amerasinghe, F, and Munasingha, N. (1988). A predevelopment mosquito survey in the Mahaweli development project area, Sri Lanka: adults. J. Med. Entomol. 25, 276-285.

Baird, J. K. (2009). Malaria zoonoses. Travel Med. Infect Dis. 7, 269-277.

Barber, B. E., William, T., Jikal, M., Jilip, J., Dhararaj, P., Menon, J., Yeo, T. W., and Anstey, N. M. (2011). Plasmodium knowlesi malaria in children. Emerging Infect. Dis. 17, 20.

Berry, A., Iriart, X., Wilhelm, N., Valentin, A., Cassaing, S., Witkowski, B., Benoit-Vical, F., Menard, S., Olagnier, D., and Fillaux, J. (2011). Imported Plasmodium knowlesi Malaria in a French tourist returning from Thailand. Am. J. Trop. Med. Hyg. 84, 535-538.

Bockarie, M. J., Pedersen, E. M., White, G. B., and Michael, E. (2009). Role of vector control in the global program to eliminate lymphatic filariasis. Annu. Rev. Entomol. 54, 469-487.

Bronner, U., Divis, P. C. S., Farnert, A., and Singh, B. (2009). Swedish traveller with Plasmodium knowlesi malaria after visiting Malaysian Borneo: a case report. Malar. J. 8, 15.

Cartel, J. L., Nguyen, N. L., Moulia-Pelat, J. P., Plichart, R., Martin, P. M. V., and Spiegel, A. (1992). Mass chemoprophylaxis of lymphatic filariasis with a single dose of ivermectin in a Polynesian community with a high Wuchereria bancrofti infection rate. Trans. R. Soc. Trop. Med. Hyg. 86, 537-540.

Chang, M. S., Doraisingam, P., Hardin, S., and Nagum, N. (1995). Malaria and filariasis transmission in a village/forest setting in Baram District, Sarawak, Malaysia. J. Trop. Med. Hyg. 98, 192.

Chareonviriyaphap, T., Bangs, M. J., and Ratanatham, S. (2000). Status of malaria in Thailand. Southeast Asian J. Trop. Med. Public Health 31, 225-237.

Cheong, W. H., and Omar, A. H. (1965). Anopheles maculatus, a new vector of Wuchereria bancrofti in Malaysia (Pulau Aur) and a potential vector on mainland Malaya. Med. J. Malaya. 20, 74.

Cheong, W. H., Warren, M. W., Omar, A. H., and Mahadevan, S. (1965). Anopheles balabacensis balabacensis identified as vector of simian malaria in Malaysia. Science 150, 1314.
Chiang, G. L., Loong, K. P., Chan, S. T., Eng, K. L., and Yap, H. H. (1991). Capture-recapture studies with Anopheles maculatus Theobald (diptera: culicidae) the vector of malaria in peninsular Malaysia. Southeast Asian J. Trop. Med. Public Health 22, 643.

Chin, W., Contacos, P. G., Coatney, G. R., and Kimball, H. R. (1965). A naturally acquired quotidian-type malaria in man transferable to monkeys. Science 149, 865.

Chin, W., Contacos, P. G., Collins, W. E., Jeter, M. H., and Alpert, E. (1968). Experimental mosquitotransmission of Plasmodium knowlesi to man and monkey. Am. J. Trop. Med. Hyg. 17, 355-358.

Choudhury, D. S., Wattal, B. L., and Ramakrishnan, S. P. (1963). Incrimination of Anopheles elegans James (1903) as a natural vector of simian malaria in the Nilgiris, Madras State, India. Indian J. Malariol. 17, 243.

Contacos, P. G. (1970). Primate malarias: man and monkeys. J. Wildl. Dis. 6, 323-328.

Conway, D. J. (2007). Molecular epidemiology of malaria. Clin. Microbiol. Rev. 20, 188.

Cox-Singh, J., Davis, T. M. E., Lee, K. S., Shamsul, S. S. G., Matusop, A., Ratnam, S., Rahman, H. A., Conway, D. J., and Singh, B. (2008). Plasmodium knowlesi malaria in humans is widely distributed and potentially life threatening. Clin. Infect. Dis. 46, 165-171.

Cox-Singh, J., and Singh, B. (2008). Knowlesi malaria: newly emergent and of public health importance? Trends Parasitol. 24, 406-410.

Cross, J. H., Partono, F., Hsu, M. Y., Ash, L. R., and Oemijati, S. (1974). "Development of Wuchereria bancrofti in the Mongolian gerbil and Taiwan monkey," in Abstracts Set B12 - Proceedings of the 3rd International Congress of Parasitology, Munich, 613.

Das, P. K., Manoharan, A., Subramanian, S., Ramaiah, K. D., Pani, S. P., Rajavel, A. R., and Rajagopalan, P. K. (1992). Bancroftian filariasis in Pondicherry, south India - epidemiological impact of recovery of the vector population. Epidemiol. Infect. 108, 483.

Dissanaike, A. S., and Mak, J. W. (1980). A description of adult Wuchereria bancrofti (rural strain) from an experimental infection in the longtailed macaque, Macaca fascicularis (Syn. M. irus). J. Helminthol. 54, 117-122.

Dreyer, G., Noroes, J., Figueredo-Silva, J., and Piessens, W. F. (2000).
Pathogenesis of lymphatic disease in Bancroftian filariasis. A clinical perspective. Parasitol. Today 16 , 544-548.

Esterre, P., Plichart, C., Sechan, Y., and Nguyen, N. L. (2001). The impact of 34 years of massive DEC chemotherapy on Wuchereria bancrofti infection and transmission: the Maupiti cohort. Trop. Med. Int. Health 6, 190-195.

Eyles, D. E., Laing, A. B. G., and Dobrovolny, C. G. (1962a). The malaria parasites of the pig-tailed macaque, Macaca nemestrina (Linnaeus). Indian J. Malariol.16, 285-298.

Eyles, D. E., Laing, A. B. G., Warren, M., and Sandosham, A. A. (1962b). Malaria parasites of the Malayan leaf monkeys of the genus Presbytis. Med. J. Malaya 17, 85-86.

Figtree, M., Lee, R., Bain, L., Kennedy, T., Mackertich, S., Urban, M., Cheng, Q., and Hudson, B. J. (2010). Plasmodium knowlesi in human, Indonesian Borneo. Emerging Infect. Dis. 14, 672-674.

Fong, Y. L., Cadigan, F. C., and Coatney, G. R. (1971). A presumptive case of naturally occurring Plasmodium knowlesi malaria in man in Malaysia. Trans. R. Soc. Trop. Med. Hyg. 65 839.

Gage, K. L., Burkot, T. R., Eisen, R. J., and Hayes, E. B. (2008). Climate and vectorborne diseases. Am. J. Prev. Med. 35, 436-450.

Galinski, M. R., and Barnwell, J. W. (2009). Monkey malaria kills four humans. Trends Parasitol. 25, 200-204.

Goh, K. T. (1983). Eradication of malaria from Singapore. Singapore Med. J. 24, 255.

Hairston, N. G., and De Meillon, B. (1968). On the inefficiency of transmission of Wuchereria bancrofti from mosquito to human host. Bull. World Health Organ. 38, 935.

Hakim, S. L., Vythilingam, I., Marzukhi, M. I., and Mak, J. W. (1995). Single-dose diethylcarbamazine in the control of periodic brugian filariasis in Peninsular Malaysia. Trans. R. Soc. Trop. Med. Hyg. 89, 686-689.

Harbach, R. (2004). The classification of genus Anopheles (diptera: culicidae): a working hypothesis of phylogenetic relationships. Bull. Entomol. Res. 94, 537-554.

Hawking, F. (1976). The distribution of human filariasis throughout the world. Part II. Asia. Trop. Dis. Bull. 73, 967.

Hay, S. I., and Snow, R. W. (2006). The Malaria atlas project: developing global maps of malaria risk.
PLoS Med. 3, e473. doi:10.1371/journal.pmed.0030473

Hii, J. L. K., Chee, K. C., Vun, Y. S., Awang, J., Chin, K. H., and Kan, S. K. (1996). Sustainability of a successful malaria surveillance and treatment program in a Runggus community in Sabah, east Malaysia. Southeast Asian J. Trop. Med. Public Health 27, 512.

Hii, J. L. K., Kan, S., Pereira, M., Parmar, S. S., Campos, R. L., and Chan, M. K. C. (1985). Bancroftian filariasis and malaria in island and hinterland populations in Sabah, Malaysia. Trop. Geogr. Med. 37, 93-101.

Hoosen, A., and Shaw, M. (2011). Plasmodium knowlesi in a traveller returning to New Zealand. Travel Med. Infect Dis. 9, 144-148.

Jiang, N., Chang, Q., Sun, X., Lu, H., Yin, J., Zhang, Z., Wahlgren, M., and Chen, Q. (2010). Co-infections with Plasmodium knowlesi and other malaria parasites, Myanmar. Emerging Infect. Dis. 16, 1476-1478.

Jongwutiwes, S., Buppan, P., Kosuvin, R., Seethamchai, S., Pattanawong, U., Sirichaisinthop, J., and Putaporntip, C. (2011). Plasmodium knowlesi malaria in humans and macaques, Thailand. Emerging Infect. Dis. 17, 1799.

Jongwutiwes, S., Putaporntip, C., Iwasaki, T., Sata, T., and Kanbara, H. (2004). Naturally acquired Plasmodium knowlesi malaria in human, Thailand. Emerging Infect. Dis. 10, 2211-2213.

Kantele, A., Marti, H., Felger, I., Muller, D., and Jokiranta, T. S. (2008). Monkey malaria in a European traveler returning from Malaysia. Emerging Infect. Dis. 14, 1434-1436.

Khim, N., Siv, S., Kim, S., Mueller, T., Fleischmann, E., Singh, B., Divis, P., Steenkeste, N., Duval, L., and Bouchier, C. (2011). Plasmodium knowlesi infection in humans, Cambodia, 2007-2010. Emerging Infect. Dis. 17, 1900.

Lee, K. S., Cox-Singh, J., Brooke, G., Matusop, A., and Singh, B. (2009a). Plasmodium knowlesi from archival blood films: further evidence that human infections are widely distributed and not newly emergent in Malaysian Borneo. Int. J. Parasitol. 39, 1125-1128.

Lee, K. S., Cox-Singh, J., and Singh, B. (2009b). Morphological features and differential counts of Plasmodium knowlesi parasites in naturally acquired human infections. Malar. J. $8,73-73$.

Lee, K. S., Divis, P. C. S., Zakaria, S. K., Matusop, A., Julin, R. A., Conway, D. J., Cox-Singh, J., 
and Singh, B. (2011). Plasmodium knowlesi: reservoir hosts and tracking the emergence in humans and macaques. PLoS Pathog. 7, e1002015. doi:10.1371/journal.ppat.1002015

Lengeler, C. (2004). Insecticide-treated bed nets and curtains for preventing malaria. Cochrane Database Syst. Rev. 2, 1-49.

Luchavez, J., Espino, F., Curameng, P., Espina, R., Bell, D., Chiodini, P., Nolder, D., Sutherland, C., Lee, K. S., and Singh, B. (2008). Human infections with Plasmodium knowlesi, the Philippines. Emerging Infect. Dis. 14, 811-813.

Mak, J. W. (1981). Filariasis in Southeast Asia. Ann. Acad. Med. Singap. 10, 112.

Mak, J. W. (1987). Epidemiology of lymphatic filariasis. Ciba Found. Symp. 127, 5-14.

Mali, S., Steele, S., Slutsker, L., and Arguin, P. M. (2008). Malaria surveillance - United States 2006. MMWR Surveill Summ. 57, 24-39.

Manguin, S., Bangs, M., Pothikasikorn, J., and Chareonviriyaphap, T. (2010). Review on global co-transmission of human Plasmodium species and Wuchereria bancrofti by Anopheles mosquitoes. Infect. Genet. Evol. 10, 159-177.

Manguin, S., Garros, C., Dusfour, I., Harbach, R. E., and Coosemans, M. (2008). Bionomics, taxonomy, and distribution of the major malaria vector taxa of (Anopheles subgenus Cellia in Southeast Asia: an updated review. Infect. Genet. Evol. 8, 489-503.

Marchand, R. P., Culleton, R., Maeno, Y., Quang, N. T., and Nakazawa, S. (2011). Co-infections of Plasmodium knowlesi, $P$. falciparum, and $P$. vivax among humans and Anopheles dirus mosquitoes, Southern Vietnam. Emerging Infect. Dis. 17, 1232-1239.

Muturi, E., Mbogo, C., and Mwangangi, J. (2006). Concomitant infections of Plasmodium falciparum and Wuchereria bancrofti on the Kenyan coast. Filaria J. 5, 8.

Nakazawa, S., Marchand, R. P., Quang, N. T., Culleton, R., Manh, N. D., and Maeno, Y. (2009). Anopheles dirus co-infection with human and monkey malaria parasites in Vietnam. Int. J. Parasitol. 39, 1533-1537.

Ng, L. C., Lee, K. S., Tan, C. H., Ooi, P. L., Lam-Phua, S. G., Lin, R., Pang, S. C., Lai, Y. L., Solhan, S., and Chan, P. P. (2010). Entomologic and molecular investigation into Plasmodium vivax transmission in Singapore, 2009. Malar. J. 9, 305.
Ottesen, E. A., Duke, B. O., Karam, M., and Behbehani, K. (1997). Strategies and tools for the control/elimination of lymphatic filariasis. Bull. World Health Organ. 75, 491.

Petney, T., Sithithaworn, P., Satrawaha, R., Grundy-Warr, C., Andrews, R., Wang, Y. C., and Feng, C. C. (2009). Potential malaria reemergence, northeastern Thailand. Emerging Infect. Dis. 15, 1330.

Rahman, W. A., Che'rus, A., and Ahmad, A. H. (1997). Malaria and Anopheles mosquitos in Malaysia. Southeast Asian J. Trop. Med. Public Health 28, 599.

Reid, J. A. (1968). Anopheline mosquitoes of Malaya and Borneo. Kuala Lumpur: Institute for Medical Research Malaysia.

Rusmartini, T., and Yuliantina, F. (2008). "Prevalence study of reemerging lymphatic filariasis in West Java, Indonesia," in Proceeding Asean Congress Tropical Medicine and Parasitology, Bangkok, Vol. 3, 125-129.

Sabbatani, S., Fiorino, S., Chili, E., and Manfredi, R. (2011). Should knowlesi malaria in Southeast Asia impose a global health alert. J. Bacteriol. Parasitol. S2, 2.

Sallum, M. A. M., Peyton, E. L., Harrison, B. A., and Wilkerson, R. C. (2005a). Revision of the Leucosphyrus group of Anopheles (cellia)(diptera, culicidae). Rev. Bras. Entomol. 49, 1-152.

Sallum, M. A. M., Peyton, E. L., and Wilkerson, R. C. (2005b). Six new species of the Anopheles leucosphyrus group, reinterpretation of an. elegans and vector implications. Med. Vet. Entomol. 19, 158-199.

Sandosham, A. A. (1984). Perspectives in medicine: malaria. Med. J. Malaysia 39, 5.

Sandosham, A. A., and Thomas, V. (1983). Malariology: With Special Reference to Malaya. Kuala Lumpur: Coronet Books.

Scanlon, J. E. (1968). Ecology of Anopheles vectors of malaria in the Oriental region. Cah. O.R.S.T.O.M. Ser. Ent. Med. 6, 237-246.

Scanlon, J. E., and Sandhinand, U. (1965). The distribution and biology of Anopheles balabacensis in Thailand (diptera: culicidae). J. Med. Entomol. 2, 61-69.

Seethamchai, S., Putaporntip, C., Malaivijitnond, S., Cui, L., and Jongwutiwes, S. (2008). Malaria and Hepatocystis species in wild macaques, Southern Thailand. Am. J. Trop. Med. Hyg. 78, 646-653.

Seng, C. M., Matusop, A., and Sen, F. K. (1999). Differences in Anopheles composition and malaria transmission in the village settlements and cultivated farming zone in Sarawak Malaysia. Southeast Asian J. Trop. Med. Public Health 30, 434-459.

Sermwittayawong, N., Singh, B., Nishibuchi, M., Sawangjaroen, N., and Vuddhakul, V. (2012). Human Plasmodium knowlesi infection in Ranong province, southwestern border of Thailand. Malar. J. 11, 36.

Singh, B., Sung, L. K., Matusop, A., Radhakrishnan, A., Shamsul, S. S. G. Cox-Singh, J., Thomas, A., and Conway, D. J. (2004). A large focus of naturally acquired Plasmodium knowlesi infections in human beings. Lancet 363, 1017-1024.

Singh, J., and Tham, A. S. (1988). Case History on Malaria Vector Control through the Application of Environmental Management in Malaysia. Geneva: World Health Organization, 1-70.

Subbarao, S. K. (2007). Anopheline Species Complexes in South and Southeast Asia, Vol. 102. New Delhi: World Health Organization Regional Office Southeast Asia.

Subbarao, S. K. (2011). Centenary celebrations article: Plasmodium knowlesi: from macaque monkeys to humans in South-east Asia and the risk of its spread in India. J. Parasit. Dis. 35, 87-93.

Sulistyaningsih, E., Fitri, L. E., Löscher, T., and Berens-Riha, N. (2010). Diagnostic difficulties with Plasmodium knowlesi infection in humans. Emerging Infect. Dis. 16, 1033.

Sunish, I. P., Rajendran, R., Mani, T. R., Munirathinam, A., Tewari, S. C., Hiriyan, J., Gajanana, A., and Satyanarayana, K. (2002). Resurgence in filarial transmission after withdrawal of mass drug administration and the relationship between antigenaemia and microfilaraemia a longitudinal study. Trop. Med. Int Health 7, 59-69.

Tan, C. H. (2008). Identification of Vectors of Plasmodium knowlesi and other Malaria Parasites, and Studies on their Bionomics in Kapit, Sarawak, Malaysia. MSc. Thesis University Malaysia, UNIMAS, Sarawak.

Tan, C. H., Vythilingam, I., Matusop, A., Chan, S. T., and Singh, B. (2008). Bionomics of Anopheles latens in Kapit, Sarawak, Malaysian Borneo in relation to the transmission of zoonotic simian malaria parasite Plasmodium knowlesi. Malar. J. 7,52 .

Tang, T. H., Salas, A., Ali-Tammam, M., Martínez, M., Lanza, M., Arroyo, E., and Rubio, J. (2010). First case of detection of Plasmodium knowlesi in Spain by real time PCR in a traveller from Southeast Asia. Malar. J. 9, 219.

Thang, N. D., Erhart, A., Speybroeck, N., Xa, N. X., Thanh, N. N., Van Ky, P., Coosemans, M., and D'alessandro, U. (2009). Long-lasting insecticidal hammocks for controlling forest malaria: a community-based trial in a rural area of central Vietnam. PLoS ONE 4, e7369. doi:10.1371/journal.pone.0007369

Triteeraprapab, S., Kanjanopas, K., Suwannadabba, S., Sangprakarn, S., Poovorawan, Y., and Scott, A. L. (2000). Transmission of the nocturnal periodic strain of Wuchereria bancrofti by Culex quinquefasciatus: establishing the potential for urban filariasis in Thailand. Epidemiol. Infect. 125, 207-212.

Trung, H. D., Van Bortel, W., Sochantha, T., Keokenchanh, K., Quang, N. T., Cong, L. D., and Coosemans, M. (2004). Malaria transmission and major malaria vectors in different geographical areas of Southeast Asia. Trop. Med. Int. Health 9 , 230-237.

Van den Eede, P., Van, H. N., Van Overmeir, C., Vythilingam, I., Duc, T. N., Hung Le, X., Manh, H. N., Anne, J., D'alessandro, U., and Erhart, A. (2009). Human Plasmodium knowlesi infections in young children in central Vietnam. Malar. J. 8, 249.

Vythilingam, I. (2010). Review Paper Plasmodium knowlesi in humans: a review on the role of its vectors in Malaysia. Trop. Biomed. 27, 1-12.

Vythilingam, I., Chan, S. T., Shanmugratnam, C., Tanrang, H., and Chooi, K. H. (2005a). The impact of development and malaria control activities on its vectors in the Kinabatangan area of Sabah, East Malaysia. Acta Trop. 96, 24-30.

Vythilingam, I., Tan, C. H., and Nazni, W. A. (2005b). Transmission potential of Wuchereria bancrofti by Culex quinquefasciatus in urban areas of Malaysia. Trop. Biomed. 22, 83-85.

Vythilingam, I., Chiang, G. L., Mahadevan, S., Eng, K. L., Chan, S. T., and Singh, K. I. (1993). Studies on the effect of lambdacyhalothrin on Anopheles maculatus Theobald and its response to residual spraying at Jeram Kedah, Negeri Sembilan, Malaysia. Southeast Asian J. Trop. Med. Public Health 24, 138-142.

Vythilingam, I., Foo, L. C., Chiang, G. L., Chan, S. T., Eng, K. L., Mahadevan, S., Mak, J. W., and Singh, K. I. (1995). The impact of permethrin impregnated bednets on the malaria 
vector Anopheles maculatus (diptera: culicidae) in aboriginal villages of Pos Betau Pahang, Malaysia. Southeast Asian J. Trop. Med. Public Health 26, 354-358.

Vythilingam, I., Hakim, S. L., Chan, S. T., and Mak, J. W. (1996). Anopheles donaldi incriminated as a vector of periodic Brugia malayi in Grik, Perak, Malaysia. Southeast Asian J. Trop. Med. Public Health 27, 637-641.

Vythilingam, I., Noorazian, Y. M., Huat, T. C., Jiram, A. I., Yusri, Y. M., Azahari, A. H., Norparina, I., Noorrain, A., and Lokmanhakim, S. (2008). Plasmodium knowlesi in humans, macaques and mosquitoes in peninsular Malaysia. Parasit. Vectors 1, 26.

Vythilingam, I., Phetsouvanh, R., Keokenchanh, K., Yengmala, V., Vanisaveth, V., Phompida, S., and Hakim, S. L. (2003). The prevalence of Anopheles (diptera: culicidae) mosquitoes in Sekong Province,
Lao PDR in relation to malaria transmission. Trop. Med. Int. Health 8, 525-535.

Vythilingam, I., Tan, C. H., Asmad, M., Chan, S. T., Lee, K. S., and Singh, B. (2006). Natural transmission of Plasmodium knowlesi to humans by Anopheles latens in Sarawak, Malaysia. Trans. R. Soc. Trop. Med. Hyg. 100, 1087-1088.

Warren, M. W., Cheong, W. H., Fredericks, H. K., and Coatney, G. R. (1970). Cycles of jungle malaria in West Malaysia. Am. J. Trop. Med. Hyg. 19, 383.

Warren, M. W., and Wharton, R. H. (1963). The vectors of simian malaria: identity, biology, and geographical distribution. J. Parasitol. 892-904.

Wharton, R. H., and Eyles, D. E. (1961). Anopheles hackeri, a vector of Plasmodium knowlesi in Malaya. Science 134, 279.

Wharton, R. H., Eyles, D. E., Warren, M., and Cheong, W. H. (1964). Studies to determine the vectors of monkey malaria in Malaya. Ann. Trop. Med. Parasitol. 58, 56.

White, N. (2008). Plasmodium knowlesi: the fifth human malaria parasite. Clin. Infect. Dis. 46, 172.

WHO. (2010). Regional Strategic Plan for Elimination of Lymphatic Filariasis 2010-2015. New Delhi: World Health Organization Regional Office Southeast Asia, $1-27$.

Witt, C., and Ottesen, E. A. (2001) Lymphatic filariasis: an infection of childhood. Trop. Med. Int. Health 6, 582-606.

Zagaria, N., and Savioli, L. (2002). Elimination of lymphatic filariasis: a public-health challenge. Ann. Trop. Med. Parasitol. 96, 3-13.

Zhu, H., Li, J., and Zheng, H. (2006). Human natural infection of Plasmodium knowlesi. Zhongguo Ji Sheng Chong Xue Yu Ji Sheng Chong Bing Za Zhi 24, 70 .
Conflict of Interest Statement: The author declares that the research was conducted in the absence of any commercial or financial relationships that could be construed as a potential conflict of interest.

Received: 19 January 2012; accepted: 08 April 2012; published online: 01 May 2012.

Citation: Vythilingam I (2012) Plasmodium knowlesi and Wuchereria ban crofti: their vectors and challenges for the future. Front. Physio. 3:115. doi: 10.3389/fphys.2012.00115

This article was submitted to Frontiers in Systems Biology, a specialty of Frontier in Physiology.

Copyright (C) 2012 Vythilingam. This is an open-access article distributed under the terms of the Creative Commons Attribution Non Commercial License, which permits non-commercial use, distribution, and reproduction in other forums, provided the original authors and source are credited. 